\title{
Graphene oxide and graphite oxide used as reinforcement in composites synthesized from cellulose acetate and polyacrylic acid
}

\section{Óxido de grafeno y óxido de grafito empleados como refuerzo en compositos sintetizados a partir de acetato de celulosa y ácido poliacrílico}

\author{
SÁNCHEZ-MÁRQUEZ, Juan†**, FUENTES-RAMÍREZ, Rosalba and RUIZ-CAMACHO, Beatriz \\ Universidad de Guanajuato, Division of Natural and Exact Sciences, Department of Chemical Engineering, Noria Alta S/N, \\ Noria Alta, 36050, Guanajuato, Guanajuato, Mexico.
}

ID $1^{\text {st }}$ Author: Juan Antonio, Sánchez-Márquez / ORC ID: 0000-0003-0138-642X, CVU CONACYT ID: 267260

ID $1^{\text {st }}$ Coauthor: Rosalba, Fuentes-Ramírez / ORC ID: 0000-0003-0520-3387, CVU CONACYT ID: 202669

ID $2^{\text {nd }}$ Coauthor: Beatriz, Ruíz-Camacho / ORC ID: 0000-0002-5524-1317, CVU CONACYT ID: 175139

DOI: $10.35429 /$ JSI.2021.16.5.6.13

Received March 14, 2021; Accepted June 29, 2021

\begin{abstract}
This work focused on the synthesis and characterization of composites, obtained based on polyacrylic acid and cellulose acetate, which incorporated graphite oxide and graphene oxide as structural reinforcement. The composites were obtained using the phase inversion method and the incorporation of the reinforcement, during the synthesis process, was carried out in proportions of $1 \%$ by weight. The characterization of the composites was carried out using IR, Raman, BET, SEM spectroscopy techniques and methods for determining acidic and basic sites. The results obtained showed that it is possible to synthesize composites that present a network configuration, made up of layers that give the material the effect of depth. Furthermore, it was possible to observe that both graphite oxide and graphene oxide were deposited on the outer edge of the hexagonal pores present in the material. Finally, the concentration values of acidic and basic sites were obtained. The presence of these sites could be associated with carboxylic groups inserted during the oxidation of graphitic materials and with non-reactive sites present in cellulose.
\end{abstract}

Graphene oxide, Cellulose Acetate, Polyacrylic Acid

\begin{abstract}
Resumen
Este trabajo se enfocó en la síntesis y caracterización de compositos, obtenidos a base de ácido poliacrílico y acetato de celulosa, los cuáles incorporaron óxido de grafito y óxido de grafeno como refuerzo estructural. Los compositos fueron obtenidos empleando el método de inversión de fases y la incorporación del refuerzo, durante el proceso de síntesis, se llevó a cabo en proporciones del $1 \%$ en peso. La caracterización de los compositos se realizó empleando técnicas de Espectroscopía IR, Raman, BET, SEM y métodos de determinación de sitios ácidos y básicos. Los resultados obtenidos mostraron que es posible sintetizar compositos que presenten una configuración en red, constituida por capas que den al material el efecto de profundidad. Además, fue posible observar que tanto el óxido de grafito como el óxido de grafeno se depositaron en el borde exterior de los poros hexagonales presentes en el material. Finalmente, los valores de concentración de sitios ácidos y básicos fueron obtenidos. La presencia de estos sitios pudo ser asociada con grupos carboxílicos insertados durante la oxidación de los materiales grafíticos y con sitios no reactivos presentes en la celulosa.
\end{abstract}

Óxido de Grafeno, Acetado de Celulosa, Ácido Poliacrílico

Citation: SÁNCHEZ-MÁRQUEZ, Juan, FUENTES-RAMÍREZ, Rosalba and RUIZ-CAMACHO, Beatriz. Graphene oxide and graphite oxide used as reinforcement in composites synthesized from cellulose acetate and polyacrylic acid. Journal of Systematic Innovation. 2021. 5-16: 6-13

\footnotetext{
* Correspondence to Author (e-mail: ja.sanchez@ugto.mx)

$\uparrow$ Researcher contributing as first author.
} 


\section{Introduction}

It is important to point that cellulose acetate is one of the most used materials in the manufacture of porous materials. (Kutowy 1975,1449). From this material we can produce membranes with low binding and adequate porosity (Park 1968, 277). Furthermore, cellulose acetate is cheap, with adequate biocompatibility and good resistance to soiling. In relation to the disadvantages of this material we can say that this material has a poor mechanical strength and low thermal and chemical resistance (Sivakumar 1999, 1647) and (Sivakumar 2000, 215). On the other hand, polyacrylic acid is a high molecular weight polymer with an outstanding ability to absorb and retain water, as well as to swell and increase many times its original volume (hydrogel). Polyacrylic acid is commonly used in the manufacture of adhesives and as a dispersing or thickening agent in paint, drug, and cosmetic manufacturing processes. This project has worked on the synthesis of composites made from polyacrylic acid and cellulose acetate that can be used as a support for graphitic materials.

Previous studies have shown that it is possible to control the porosity of materials obtained from the crosslinking reaction of cellulose acetate and polyacrylic acid, just by varying the time of immersion in hot water. The pore diameter ranges from 3 to 100 microns in these materials, and it shows a nonlinear behaviour as a function of the temperature of the immersion medium (Estrada 2010, 3). The possibility of controlling the pore through an external factor, such as the variation of water temperature immersion, enhances the possible applications of these materials.

Graphene is one of the most important carbon nanostructures due to its outstanding physical and chemical properties. Graphene has a unique two-dimensional structure of superimposed layers that makes it attractive for multiple applications (Rao 2009, 7752), (Geim 2007, 183) and (Kovtyukhova 1992, 566). The mass production of graphene oxide (GO) has been possible from chemical methods (Hummers' Method) that include oxidation and the subsequent reduction of this compound to produce reduced graphene oxide (RGO). These procedures have favoured the search for applications for these materials (Sreeprasad 2011, 921).
However, it is important to note that to take advantage of the outstanding properties of graphene, we must consider that these materials need to be supported on other materials to obtain attractive composite structures with a better performance than the performance showed by pure initial components.

Thus, the addition of fillers in polymers is an attractive method to obtain materials with novel properties. The use of polymers provides support to graphene oxide and permits its use in continuous processes and new applications such as the adsorption of heavy metals (Gadupudi 2007, 224), (Tuzen 2007, 219) and ( $\mathrm{Hu} 2009$, 1542).

\section{Methodology}

\section{Graphene oxide synthesis (OG)}

Graphene oxide was obtained from crystalline graphite (Electron Microscope Science, No. 70230). The graphite was oxidized using the improved method of Hummers (Bin 2011, 31). This method allows obtaining graphite oxide using a mixture of graphite, sulfuric acid (Jalmek, purity: 95-98 \%, MW = $98.08 \mathrm{~g} \mathrm{~mol}^{-1}$ ) and potassium permanganate (JT Baker). The oxidation reaction was conducted at $35{ }^{\circ} \mathrm{C}$, with a range of $+/-3{ }^{\circ} \mathrm{C}$, for $2 \mathrm{~h}$, with a constant medium agitation. Then, the flask was removed from the heat and $92 \mathrm{~mL}$ of distilled water was slowly added to the flask.

The solution was kept under magnetic stirring for $15 \mathrm{~min}$. Next, a mixture of $270 \mathrm{~mL}$ of distilled water and $10 \mathrm{~mL}$ of hydrogen peroxide (J. T Baker, 30\% weight) was added. The final solution was washed with distilled water and the material obtained was dried at $65{ }^{\circ} \mathrm{C}\left(+/-2{ }^{\circ} \mathrm{C}\right)$ for $12 \mathrm{~h}$. Graphene oxide was obtained from a sample of graphite oxide. The sample of graphite oxide was mixed with distilled water. This mixture was placed in an ultrasonic bath (Branson, Model 1510R-MTH) for $3 \mathrm{~h}$ at a frequency of 50-60 Hz. After this time, the solution was filtered and dried for later use. 


\section{Synthesis of composite from cellulose acetate and polyacrylic acid}

For the synthesis of the composites, the following chemical reagents were used: cellulose acetate (Sigma Aldrich) with a molecular weight of 50,000 by Gel permeation chromatography (GPC) and a degree of acetylation of $39.7 \%$ weight, and polyacrylic acid in aqueous solution (Sigma Aldrich) with a molecular weight of $30000 \mathrm{~g} \mathrm{~mol}^{-1}$ and a percentage of $35 \%$ weight. All commercial reagents were used without any further purification step. Composite was prepared according to a procedure previously reported (Estrada 2010, 3). Initially, a solution was prepared dissolving $8 \mathrm{~g}$ of cellulose acetate in $100 \mathrm{~mL}$ of glacial acetic acid at room temperature.

Then, when the cellulose acetate had been completely dissolved, $10 \mathrm{~mL}$ of polyacrylic acid was added slowly with a constant medium agitation; this solution was heated at $60{ }^{\circ} \mathrm{C}$ under agitation for $30 \mathrm{~min}$, allowing the crosslinking reaction between the cellulose acetate and the polyacrylic acid to take place. The final solution was cooled down to room temperature and stored for 3 days before use. To obtain the composites, several samples were poured into flat glad molds of $10 \mathrm{~cm}$ in diameter, leaving the molds with the solution floating on iced water at $4{ }^{\circ} \mathrm{C}$, allowing the solution to reach the same temperature of iced water.

Thereafter, the mold with the polymer solution was completely immersed carefully into the cold water until the composites formed and subsequently permitted to rest for $15 \mathrm{~min}$ to allow the solidification of polymer solution. Once the composites were formed, they were withdrawn from the iced water and immediately placed into a bath of hot water at $60{ }^{\circ} \mathrm{C}$. This procedure was applied to composites both with and without graphene oxide using concentrations of $1 \%$ by weight.

\section{Surface Characterization}

The characterization of polymer and graphene oxide was made by Fourier Transform Infrared spectroscopy with attenuated total reflectance (FTIR-ATR Vertex Model 70) in pressed $\mathrm{KBr}$ pellets $(100 \mathrm{mg} \mathrm{KBr}$ and $1 \mathrm{mg}$ of sample) of graphitic materials.
For FTIR spectroscopy, the samples were dried at $333 \mathrm{~K}$ for $24 \mathrm{~h}$. The characterization by FTIR was complemented with a Raman analysis (Renishaw Raman Microscope Invia Reflex, Wotton-under-Edge, UK). Raman spectroscopy is a technique that offers numerous advantages in the chemical and structural analysis of the molecular networks of any material. This methodology relates values obtained from Raman spectra with structural characteristics of the material, based on bibliographic references (Bagheri 2021, 33).

The morphology of crosslinked polymer was investigated with the aid of the scanning electron microscope (Jeol JSM-6610LV) operated in the high vacuum mode at an acceleration voltage of $20 \mathrm{kV}$ and a pressure of $20 \mathrm{~Pa}$, the materials were previously coated with gold. The SEM images to the rest of materials were determined with an environmental scanning electron microscope (MEBA, PHILIPS: Model XL30) operated in the high vacuum mode too. The effective surface area and pore size distribution of the graphite materials were determined using N2-BET (ASAP 2010 V5.03). Finally, the surface charge and point of zero charge of the materials were evaluated using a potentiometric titration method proposed by Loskutov and Kuzin and the concentrations of acidic and basic sites were calculated using the equations proposed by Böehm.

\section{Results}

\section{Infrared spectroscopy (FTIR-ATR)}

The IR spectra of the mineral graphite and graphite oxide are compared in Graphic 1. The spectrum for mineral graphite shows peaks at 1300 and $1100 \mathrm{~cm}^{-1}$ associated with stretching vibrations of C-C bond and a peak at $1670 \mathrm{~cm}^{-1}$ associated with stretching vibrations of $\mathrm{C}=\mathrm{C}$ bond. After the oxidation reaction, the spectrum for graphite oxide shows a peak at $3348 \mathrm{~cm}^{-1}$ associated with the stretching vibration of the $\mathrm{OH}$ bond in the water molecules present between the layers of graphite oxide. In addition, the peak at $1720 \mathrm{~cm}^{-1}$ is associated with the stretching of the carbonyl group $(\mathrm{C}=\mathrm{O})$ and the signal at 1589 $\mathrm{cm}-1$ is attributed to the stretching of double bonds $(\mathrm{C}=\mathrm{C})$ of the graphite ring. Finally, the characteristic signals of the epoxy group (C-OC) were observed at 1224 and $804 \mathrm{~cm}^{-1}$ and the stretching vibrations of the $\mathrm{C}-\mathrm{OH}$ bond was observed at $1053 \mathrm{~cm}^{-1}$. 


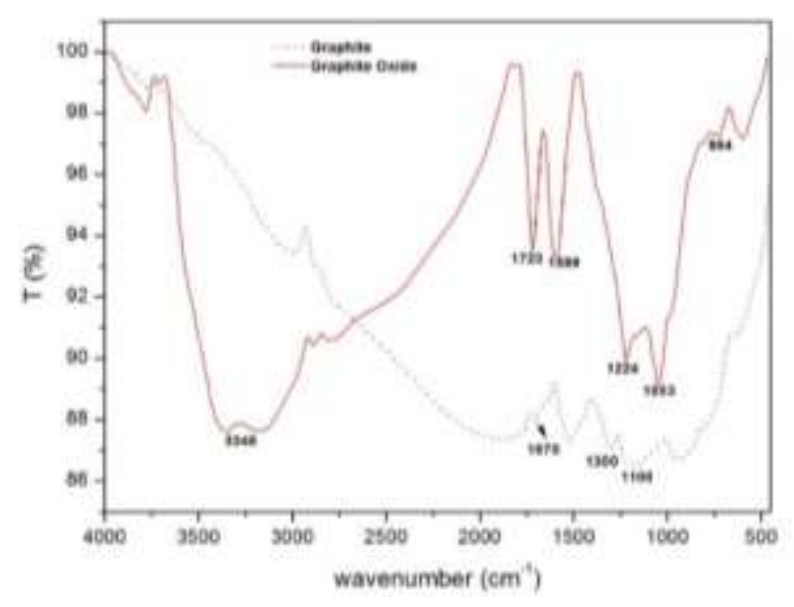

Graphic 1 Infrared spectra of graphite and graphite oxide

The IR spectra of graphite oxide and graphene oxide show functional groups with presence of oxygen. However, the graphene oxide shows more definite signs due to the reduced number of layers of material, Graphic 2.

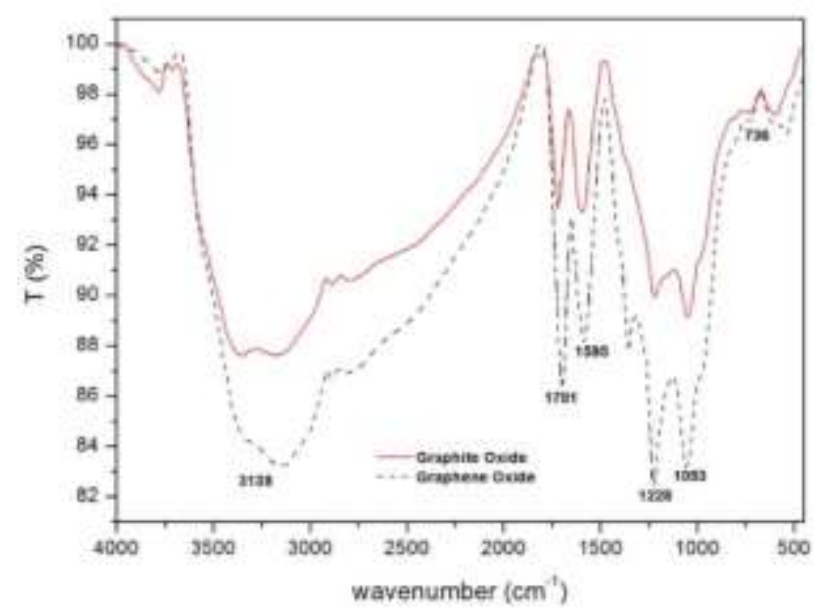

Graphic 2 Infrared spectra of graphite oxide and graphene oxide

\section{Crosslinked Polymer}

Molecular interactions between materials were studied by obtaining their FTIR spectra. The IR spectra of cellulose acetate, polyacrylic acid and the crosslinked polymer are shown in Graphic 3. The spectrum for polyacrylic acid shows the typical bands for carboxylic acids, with the stretching absorption associated with the hydroxyl groups $(\mathrm{O}-\mathrm{H})$ in $3384 \mathrm{~cm}^{-1}$, while the carbon-oxygen $\quad(\mathrm{C}=\mathrm{O})$ absorption peak characteristic of carbonyl was observed at 1701 $\mathrm{cm}^{-1}$. In addition, peaks for $\mathrm{C}=\mathrm{C}$ and $\mathrm{C}-\mathrm{C}$ stretching were observed at 1629 and $1234 \mathrm{~cm}^{-1}$. Finally, the band in $1452 \mathrm{~cm}^{-1}$ can be assigned to the in-plane bending of the hydroxyl group.
The spectrum for cellulose acetate also showed an absorption band associated to the $\mathrm{OH}$ stretching region in $3487 \mathrm{~cm}^{-1}$, while the carbon-oxygen $\quad(\mathrm{C}=\mathrm{O})$ absorption peak characteristic of carbonyl was observed at 1756 $\mathrm{cm}^{-1}$. Peaks observed at $2958 \mathrm{~cm}^{-1}$ could be attributed to symmetric and asymmetric stretching vibrations while the signals placed at 1436 and $1368 \mathrm{~cm}^{-1}$ can be attributed to symmetric and asymmetric bending vibrations of the carbon-hydrogen bonds present in the methyl group.

Peaks observed between 1227 and 1048 $\mathrm{cm}^{-1}$ are characteristic of materials based on cellulose and they can be associated with the carboxylate group, the link between rings C-O$\mathrm{C}$ and the pyranose ring, respectively. Finally, the band in $903 \mathrm{~cm}^{-1}$ cans be assigned to the outplane bending of hydroxyl group. When the cellulose acetate and polyacrylic acid reacted, the bands associated with the carboxylic groups $(\mathrm{C}=\mathrm{O}$ and $\mathrm{OH})$ of the polyacrylic acid and the hydroxyl and acetyl groups of the cellulose acetate decrease significantly.

This proves that the crosslinking reaction between the polyacrylic acid and the cellulose acetate has occurred. Different graphitic materials were added to the crosslinked polymer. The IR spectra of polymer with materials made from graphite are shown in Graphic 4. These spectra show the characteristic peaks of the polymer crosslinked. In addition, it is not possible to observe interactions between the polymer and graphite materials from IR spectra.

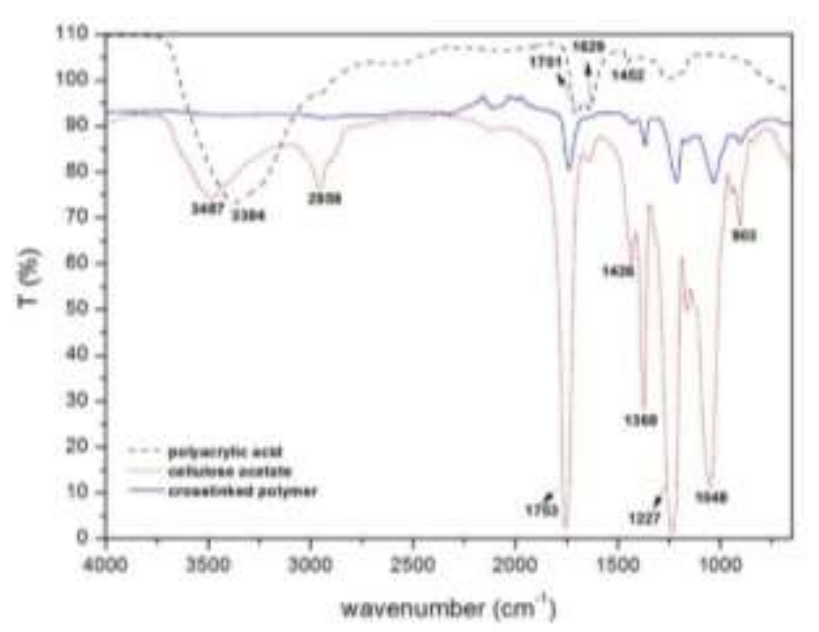

Graphic 3 Infrared spectra of synthesized composite 


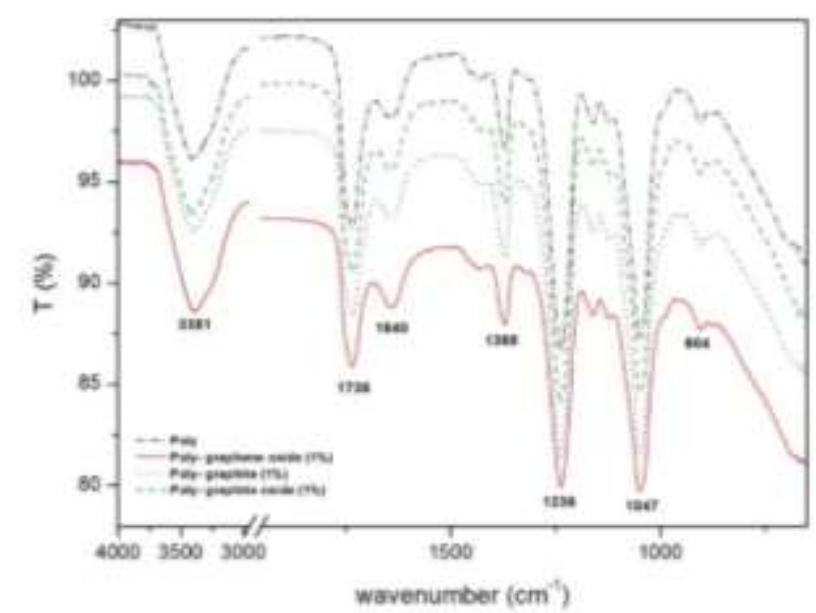

Graphic 4 Infrared spectra of the crosslinked polymer with graphite, graphite oxide and graphene oxide

\section{Raman spectroscopy}

The most intense peaks observed for mineral graphite can be seen in Graphic 5. The peak at $1352 \mathrm{~cm}^{-1}$ (D1 band) is very small. It can be attributed to the graphite does not present many structural defects or impurities. In addition, the $\mathrm{G}$ band $\left(1573 \mathrm{~cm}^{-1}\right)$ can be associated with the stretching vibration in hybridized carbon bond (C-C, sp2). This peak is the band that characterizes the mineral graphite. Finally, the peaks at $2719 \mathrm{~cm}^{-1}$ and $2436 \mathrm{~cm}^{-1}$ are known as S1 and S3, respectively.

The $\mathrm{S} 1$ band is considered an overtone associated with D1 band while S3 band is generated from transverse vibrations to the plane of graphite crystal and stretching vibrations in hybridized carbon bond. After chemical modification we can see a decrease in the order band ( $\mathrm{G}$ band) and an increased in the disorder band ( $\mathrm{D}$ band) with respect to that observed in graphite, Graphic 6.

The decrease in crystallinity may be due to the progressive incorporation of oxygen molecules between the graphene layers which make up the crystalline structure of graphite. Both graphite oxide to graphene oxide, an increase in the disorder causes second order bands ( $\mathrm{S} 1$ and $\mathrm{G}+\mathrm{D}$ band) begin to expand and lose intensity.

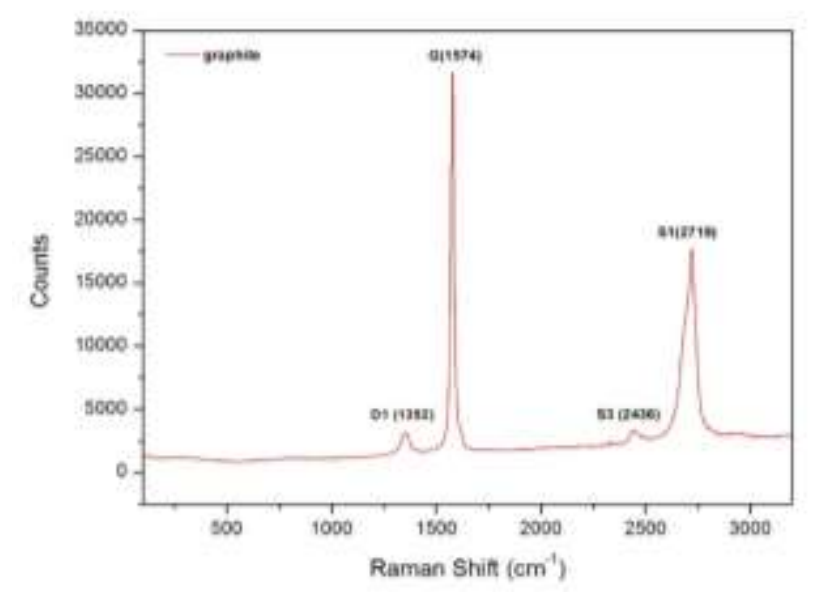

Graphic 5 Raman spectra of the mineral graphite

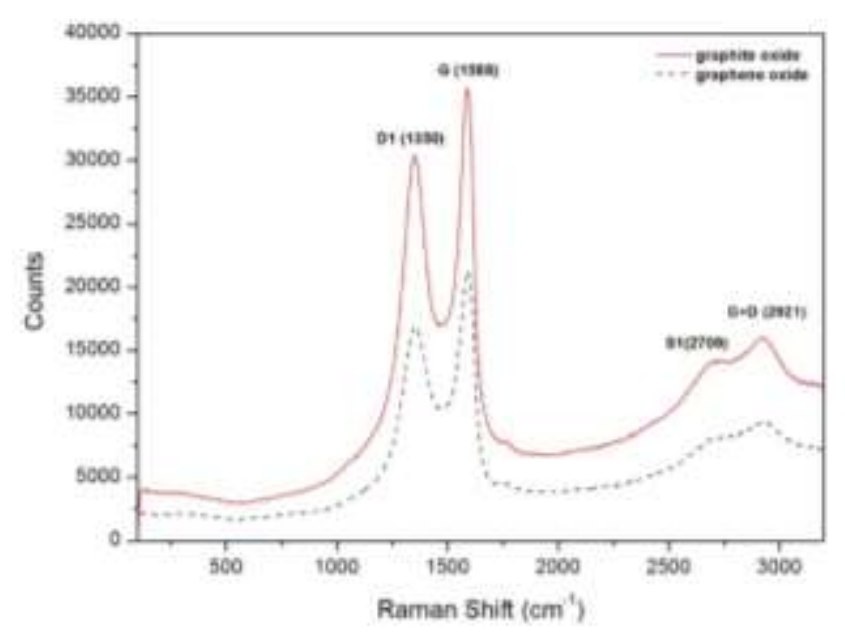

Graphic 6 Raman spectra of the graphite oxide and graphene oxide

\section{Crosslinked Polymer Synthesis}

When the crosslinking reaction takes place, the spectrum obtained shows primarily the characteristic Raman signals for the cellulose acetate while polyacrylic acid has remained undetected because their bands partially overlapped those of cellulose acetate, Graphic 7.

The characteristic Raman signals for crosslinked polymer were present at 2939 and $1121 \mathrm{~cm}^{-1}$, which are attributed to $\mathrm{C}-\mathrm{H}$ stretching and asymmetric stretching vibration of the $\mathrm{C}-\mathrm{O}-$ $\mathrm{C}$ glycosidic linkage, respectively. In addition, we observed the pyranose ring signal at $1081 \mathrm{~cm}^{-}$ ${ }^{1}$ and the characteristic Raman signals for the acetyl group in 1731 corresponding to vibration of the carbonyl group $(\mathrm{C}=\mathrm{O})$ and asymmetric and symmetric vibrations of the $\mathrm{C}-\mathrm{H}$ bond present in the acetyl groups, in 1431 and 1368 $\mathrm{cm}^{-1}$ respectively. Finally, the signals observed at $978,906,834$ and 659 can be associated with $\mathrm{C}-\mathrm{O}, \mathrm{C}-\mathrm{H}$, and $\mathrm{O}-\mathrm{H}$ and $\mathrm{C}-\mathrm{OH}$ bonds, respectively.

SÁNCHEZ-MÁRQUEZ, Juan, FUENTES-RAMÍREZ, Rosalba and RUIZ-CAMACHO, Beatriz. Graphene oxide and graphite oxide used as reinforcement in composites synthesized from cellulose acetate and polyacrylic acid. Journal of Systematic Innovation. 2021 
For crosslinked polymer we cannot observed the band associated with the $\mathrm{C}-\mathrm{OH}$ bonds present in the glycosidic rings at $1265 \mathrm{~cm}$ 1 and we cannot see the characteristic Raman signals at 3444 and $1678 \mathrm{~cm}^{-1}$ corresponding with the oxygen-hydrogen bond vibration and carbonyl group $(\mathrm{C}=\mathrm{O})$ vibration present in the polyacrylic acid neither.

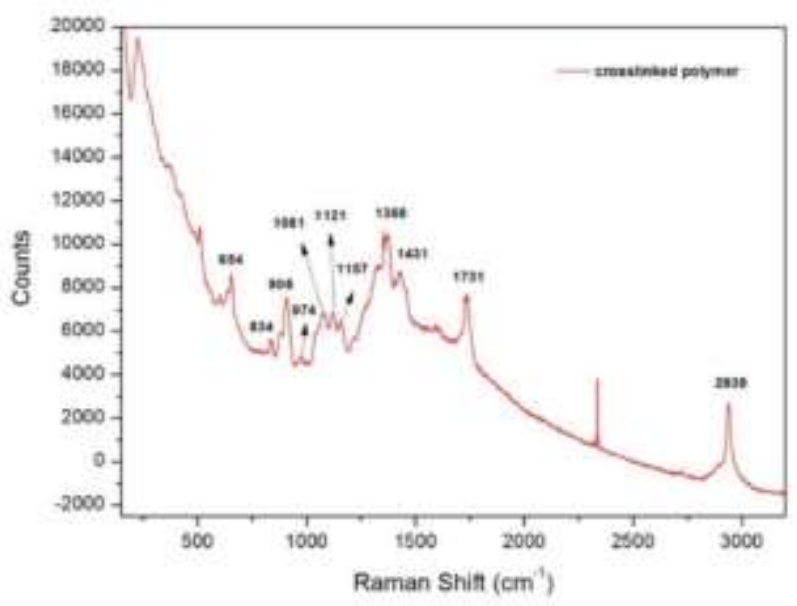

Graphic 7 Raman spectrum for the crosslinked polymer

For polymer crosslinked with different concentrations of graphite we cannot observe signals associated with graphitic materials. When we added graphite oxide or graphene oxide to the crosslinked polymer, we can observe a signal at $1592 \mathrm{~cm}^{-1}$ associated with the order band ( $\mathrm{G}$ band). The signal strength is stronger when the concentration increases, Graphic 8-10.

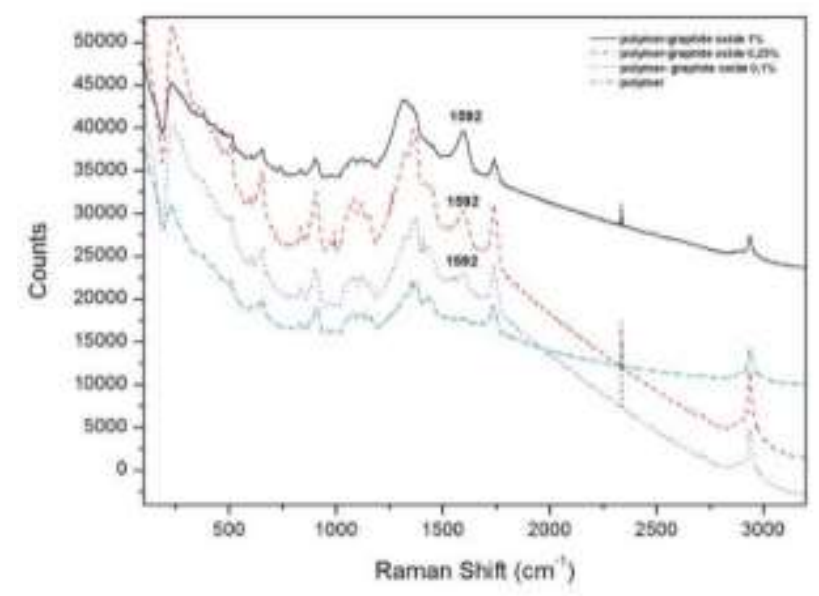

Graphic 8 Raman spectrum for the crosslinked polymer with graphite oxide

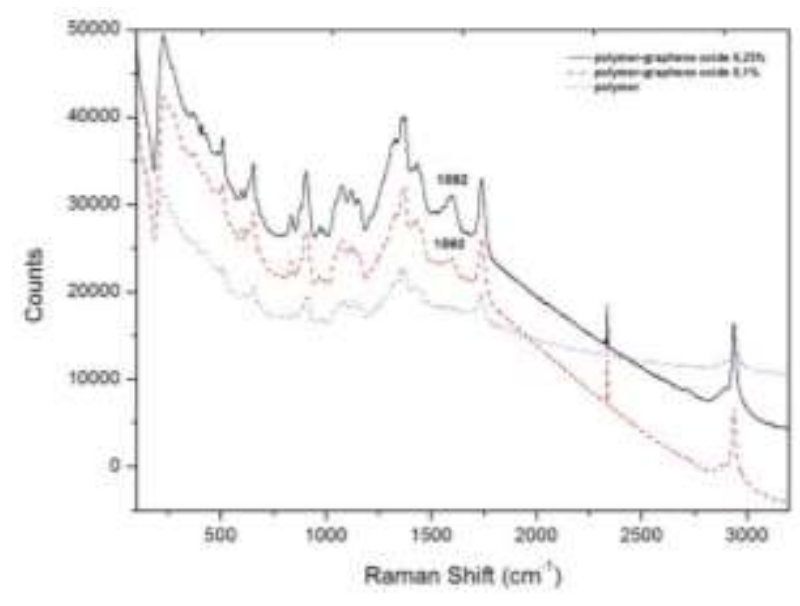

Graphic 9 Raman spectrum for the crosslinked polymer with graphene oxide

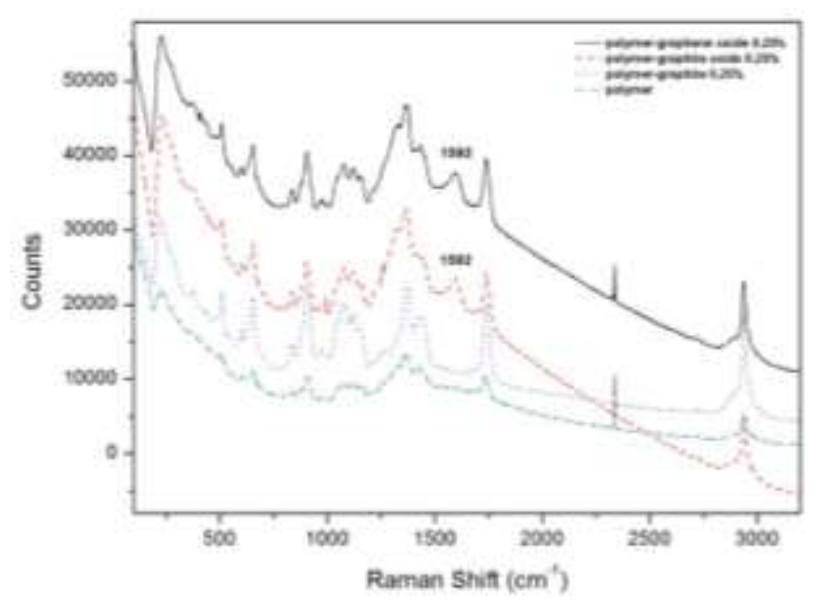

Graphic 10 Raman spectrum for the crosslinked polymer with graphite, graphite oxide and graphene oxide $(0.25 \%$ wt)

\section{Scanning Electron Microscopy}

The images obtained from electron microscopy are shown in Graphic 11. The figures correspond to the different kind of membranes synthetized. In accordance with the results obtained from the microscopic characterization, we can say that the polymeric membranes have pores of variable size. In some membranes, the pores are formed in layers, giving the effect of forming a deep network, 11a-11b. For the materials obtained from graphite we can observed that the graphitic material is deposited on the walls of the pores within the polymer structure, Figure 11c and 11f, respectively. Both graphite oxide as graphene oxide cover the walls of the material and they improve the structure polymer. 


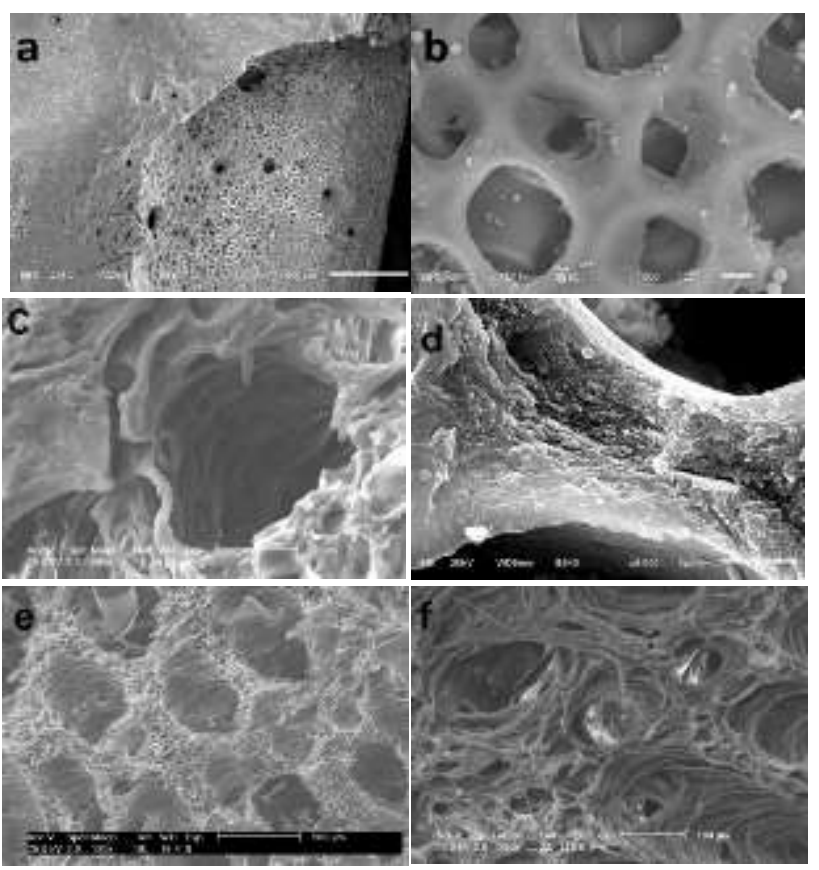

Graphic 11 Sequence of scanning electron microscope images for different polymeric materials. (a), (c) and (e) Graphite oxide, (b), (d) and (f) Graphene oxide

\section{Determination of the surface area and pore size distribution in the graphene oxide}

The BET analysis was applied to graphene oxide to determine the effective surface area and the pore size distribution of the material. The effective surface area of graphite $\left(7.73 \mathrm{~m}^{2} / \mathrm{g}\right)$, graphite oxide $\left(2.85 \mathrm{~m}^{2} / \mathrm{g}\right)$ and graphene oxide $\left(20.86 \mathrm{~m}^{2} / \mathrm{g}\right)$ were calculated with the same method. The average pore size for samples of graphite $(9.4 \mathrm{~nm})$, graphite oxide $(8.9 \mathrm{~nm})$ and graphene oxide $(10 \mathrm{~nm})$ showed small variations. In the case of graphene oxide, the adsorption-desorption isotherms obtained by BET analysis, Graphic 12, showed a characteristic behaviour of the isotherm of type 3 proposed by Brunauer, which shows that the adsorption occurs by a physical mechanism.

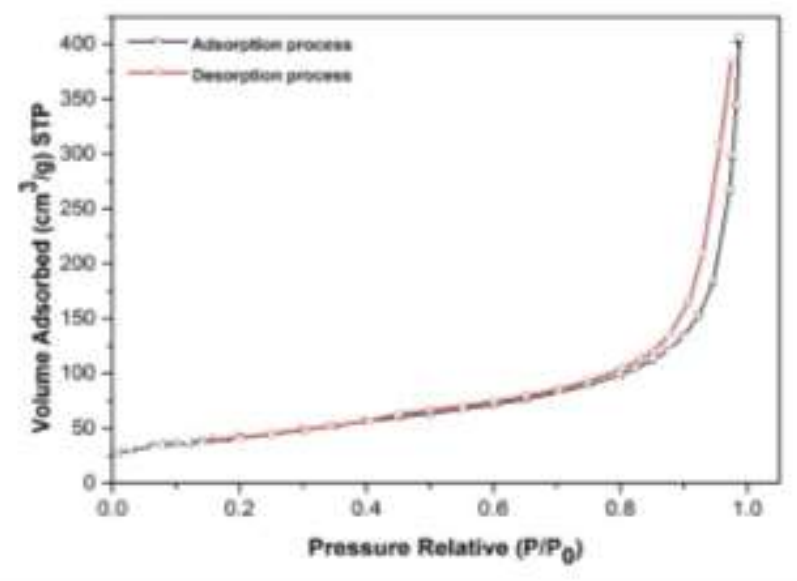

Graphic 12 Adsorption-desorption isotherm of graphene oxide
From adsorption-desorption isotherms obtained we can see that the analysed samples have a hexagonal tubular capillary.

\section{Concentration of acidic sites and basic sites}

Both, acidic and basic sites were calculated in graphene oxide and polymeric materials using a method proposed by Böehm based in an acidbase titration. For the graphite oxide and graphene oxide, concentration values for only the acid sites were obtained. The graphene oxide $(2.28 \mathrm{meq} / \mathrm{g})$ showed a higher concentration of acid sites than graphite oxide $(1.45 \mathrm{meq} / \mathrm{g})$. Both, acidic and basic sites on the membranes without graphitic material were calculated using the method proposed by Böehm. The concentration of acidic sites in the polymeric material $(4.9 \mathrm{meq} / \mathrm{g})$ is 1.25 times higher than the concentration of base sites $(3.9 \mathrm{meq} / \mathrm{g})$. The basic sites in the polymeric material may be associated with unreacted sites on the cellulose; while the acid sites can be ascribed to sites vacated in the polyacrylic acid during the synthesis process of the copolymer. For the membranes with graphitic materials, significant changes in the concentration values of the sites were not observed.

\section{Conclusions}

The results obtained show that it is possible to design polymeric composites with graphitic materials whose pores are formed in layers, giving the effect of depth forming a network. The graphitic material is deposited on the outside of the polymeric material. The adsorption-desorption isotherms obtained by BET analysis showed that the adsorption occurs by a physical mechanism and that the analysed samples have a hexagonal tubular capillary. Besides, the isotherms of adsorption / desorption obtained for graphite, graphite oxide and graphene oxide showed characteristics like the carbon nanotubes or graphite.

For the graphite, graphite oxide and graphene oxide, concentration values for only the acid sites were obtained. These acid sites can be associated with the presence of carboxylic groups inserted during oxidation of the graphitic materials. The basic sites in the polymeric material may be associated with unreacted sites on the cellulose; while the acid sites can be ascribed to sites vacated in the polyacrylic acid during the synthesis process of the copolymer. 
For the composites with graphitic materials, no significant changes were observed in the concentration values of the sites.

\section{Acknowledgement}

This work was supported by the Universidad de Guanajuato and PRODEP Program. We thank M.T. Carrillo for her help in revising the manuscript.

\section{References}

Bagheri, S. (2021). Caracterización de nanocomposites de óxido de grafeno y polimetilmetacrilato mediante espectroscopía Raman; Universidad Politécnica de Cartagena.

Bin W., Yan-Hong C., Lin-jie Z. (2011), High yield production of graphene and its improved property in detecting heavy metal ions, University of Science and Technology of Beijing, China, New Carbon Materials, 26(1), 31-35.

Estrada R., Rubio E., Rodríguez V. (2010), Nonlinear changes in pore size induced by temperature in the design of Smart membranes, Polymer Journal, 1-5.

Gadupudi R., Chungsying L., Fengsheng S. (2007), Sorption of divalent metal ions from aqueous solution by carbon nanotubes: A review, Application of Nanotechnologies in Separation and Purification, 58, 224-231.

Geim A.K., Novoselov K.S. (2007), The rise of graphene, Nat. Mater. 6, 183-191.

Hu J., Chen C., Zhu X., Wang X. (2009), Removal of chromium from aqueous solution by using oxidized multiwalled carbon nanotubes. Journal of Hazardous Materials 162, 1542-1550

Hu W., Peng C., Luo W., Lv M., Li X., Li D., Huang Q., Fan C. (2010), Graphene-based antibacterial paper, ACS Nano 4, 4317-4323.

Kovtyukhova N.I., Karpenko G.A., Chuiko A.A. (1992), Complex formation by transition metal ions in aqueous suspensions of graphite oxide, Russ. J. Inorg. Chem. 37, 566-569.

Kutowy O., Sourirajan S. (1975), Cellulose acetate ultrafiltration membranes, J. Appl. Polym. Sci. 19, 1449-1460.
Park, S. \& Crank, J. (1968), Diffusion in Polymers, Academic Press, NY, 277-319.

Rao C.N.R., Sood A.K., Subrahmanyam K.S., Govindaraj A. (2009), Graphene: the new twodimensional nanomaterial, Angew. Chem. Int. Ed. 48, 7752-7777.

Sivakumar M., Mohan D., Rangarajan R. (1998), Preparation and performance of cellulose acetate-polyurethane blend membranes and their applications. Part 1, Polym. Int. 47, 311316.

Sivakumar M., Mohan D.R., Rangarajan R. (2006), Studies on cellulose acetatepolysulfone ultrafiltration membranes. II. Effect of additive concentration, J. Membr. Sci. 268, 208-219.

Sivakumar M., Malaisamy R., Sajitha C.J., Mohan D., Mohan V., Rangarajan R. (1999), Ultrafiltration application of cellulose acetatepolyurethane blend membranes, Eur. Polym. J. 35, 1647-1651.

Sivakumar M., Malaisamy R., Sajitha C.J., Mohan D., Mohan V., Rangarajan R. (2000), Preparation and performance of cellulose acetate-polyurethane blend membrane and their applications-II, J. Membr. Sci. 169, 215-228.

Sreeprasad T.S., Maliyekkal SM, Lisha KP, Pradeep T. (2011), Reduced graphene oxidemetal/metal oxide composites: Facile synthesis and application in water purification, India, Journal of Hazardous Materials 186, 921-931.

Tuzen M., Soylak M. (2007), Multiwalled carbon nanotubes for speciation of chromium in environmental samples, Journal of Hazardous Materials 147, 219-225 